

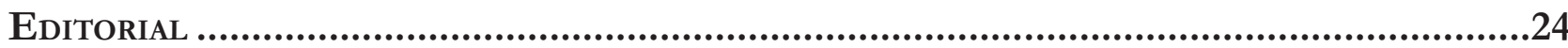

O Direito na fronteira da razão: Psicologia, neurociência e economia comportamental................... 24 Patrícia Perrone Campos Mello e Sergio Nojiri

I. NeURodireito: COGNIÇão, EMOÇÃo, JUÍZOS MORAIS E CIÊNCIA ..........................................26

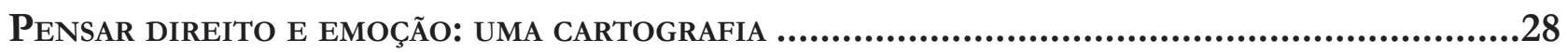

Nevita Maria Pessoa de Aquino Franca Luna

Neurodireito: o início, o fim E O MEIO

Carlos Marden e Leonardo Martins Wykrota

ENSAIO JURÍDICO SOBRE A RACIONALIDADE HUMANA: MAIORES, CAPAZES E IRRACIONAIS

André Perin Schmidt Neto e Eugênio Facchini Neto

DIVERGÊNCIAS DE PRINCÍPIO: ARGUMENTOS JURÍDICOS E MORAIS EM UM CENÁRIO DE DESACORDOS SOCIAIS

André Matos de Almeida Oliveira, Pâmela de Rezende Côrtes e Leonardo Martins Wykrota

CONSILIÊNCIA E A POSSIBILIDADE DO NEURODIREITO: DA DESCONFIANÇA À RECONCILIAÇÃO DISCIPLINAR.....

Thaís de Bessa Gontijo de Oliveira e Renato César Cardoso

MODELOS DE MORALIDADE

Molly J. Crockett

A INFELIZ BUSCA POR FELICIDADE No DiREITo

Úrsula Simões da Costa Cunha Vasconcellost, Noel Struchiner e Ivar Hannikainen

Além da liberdade: PersPeCtivas Em Nietzsche.

Lucas Costa de Oliveira

A mediaÇão de CONFlitos SOb a PERSPECTIVA do DESENVOLVIMENTO HUMANO: AS CONTRIBUIÇÕES DA PSICOLOGIA POSITIVA

Simone de Biazzi Ávila Batista da Silveira e Deise Brião Ferraz

Neuroimagiologia e aValiação de ResPonsabilidade

Nicole A. Vincent 
ANÁLISE CRÍTICA DA ORIENTAÇÃO DE CIDADÃOS COMO MÉTODO PARA OTIMIZAR DECISÕES PÚBLICAS POR MEIO DA TÉCNICA NUDGE.

Luciana Cristina Souza, Karen Tobias França Ramos e Sônia Carolina Romão Viana Perdigão

Políticas públicas e o deVer de monitoramento: “LEVANdo os Direitos A SÉrio". .252 Ana Paula de Barcellos

Nudges E POLÍticas PÚblicas: uM MECANISMO DE COMBATE AO TRABALHO EM CONDIÇÃo ANÁLOGA À DE ESCRAVO .267

Amanda Carolina Souza Silva, Débhora Renata Nunes Rodrigues e Saul Duarte Tibaldi

REDUZINDO A TRIBUTAÇÃO COGNITIVA: LIÇÕES COMPORTAMENTAIS PARA A DIMINUIÇÃO DOS EFEITOS PSICOLÓGICOS ADVERSOS DA POBREZA.............................................................288 Leandro Novais e Silva, Luiz Felipe Drummond Teixeira, Gabriel Salgueiro Soares e Otávio Augusto Andrade Santos

Políticas PÚBLICAS EM SUICÍDIO: DO PATERNALISMO CLÁSSICO AO PATERNALISMO LIBERTÁRIO E NUDGING

Davi de Paiva Costa Tangerino, Gabriel Cabral e Henrique Olive

Nudges COMO POLÍticA PÚbliCA PARA AUMENTAR O ESCASSO NÚMERO DE DOADORES DE ÓRGÃos PARA TRANSPLANTE

Roberta Marina Cioatto e Adriana de Alencar Gomes Pinheiro

Os PROGRAMAS DE INTEGRIDADE PARA CONTRATAÇÃO COM A ADMINISTRAÇÃO PÚBLICA ESTADUAL: NUDGE OU OBRIGAÇÃo LEGAL? UM OLHAR SOBRE AS DUAS PERSPECTIVAS .386

Cíntia Muniz Rebouças de Alencar Araripe e Raquel Cavalcanti Ramos Machado

Paternalismo libertário e Proteção JURídica do AMbiente: POR QUe PROTEger o AMBIENTE TAMBÉM DEVE SER PROTEGER AS LIBERDADES?

Mariana Carvalho Victor Coelho e Patryck de Araujo Ayala

Políticas PÚblicas baseadas EM EVIdÊNCIAS COMPORTAMENTAIS: REFLEXões A PARTIR do Projeto de Lei 488/2017 do Senado

Pâmela de Rezende Côrtes, André Matos de Almeida Oliveira e Fabiano Teodoro de Rezende Lara

III. ECONOMIA COMPORTAMENTAL: VIESES COGNITIVOS E POLÍTICAS PÚBLICAS .455

ECONOMIA COMPORTAMENTAL E DIREITO: A RACIONALIDADE EM MUDANÇA Marcia Carla Pereira Ribeiro e Victor Hugo Domingues

VIESES COGNITIVOS E DESENHO DE POLÍTICAS PÚBLICAS 
A neurociênCia da moralidade na tomada de DeCisões Jurídicas Complexas e No DESENHO DE POLÍTICAS PÚBLICAS

Erik Navarro Wolkart

Desvio de CARÁter ou SIMPLESMENTE HUMANO? ECONOMIA COMPORTAMENTAL APLICADA AO COMPORTAMENTO DESONESTO

Diana Orghian, Gabriel Cabral, André Pinto e Alessandra Fontana

Políticas Públicas e a ConcretizaÇão de direitos sociais: TOMAdA DE DECisão, ARQUITETURA DE ESCOLHAS E EFETIVIDADE

Ana Elizabeth Neirão Reymão e Ricardo dos Santos Caçapietra

BEHAVIORAL ECONOMICS E DIREITO DO CONSUMIDOR: NOVAS PERSPECTIVAS PARA O ENFRENTAMENTO DO SUPERENDIVIDAMENTO .568

Samir Alves Daura

A EDUCAÇÃo FORMAL PARA O CONSUMO É GARANTIA PARA UMA PRESENÇA REFLETIDA DO CONSUMIDOR NO MERCADO? UMA ANÁLISE COM BASE NA BEHAVIORAL LAW AND ECONOMICS (ECONOMIA COMPORTAMENTAL) 600

Marcia Carla Pereira Ribeiro e Edson Mitsuo Tiujo

LIBET, DETERMINISMO E CONSUMO: AS INFLUÊNCIAS DO MARKETING E A RELEVÂNCIA DA DELIBERAÇÃo CONSCIENTE NA SUPERAÇÃo CONDICIONAL DE HÁBITOS DE CONSUMO PERIGOSOS616 Émilien Vilas Boas Reis e Leonardo Cordeiro de Gusmão

CiÊNCIA DO DIREITO TRIBUTÁRIO, ECONOMIA COMPORTAMENTAL E EXTRAFISCALIDADE. .640 Hugo de Brito Machado Segundo

IV. CoMportamento JUdiCiAL: INFLUÊNCIA DE FATORES EXTRAJURÍDicos .660

FATORES METAPROCESSUAIS E SUAS INFLUÊNCIAS PARA A FORMAÇÃo DA DECISÃo JUDICIAL .662 Rogério Roberto Gonçalves de Abreu, Lúcio Grassi de Gouveia e Virgínia Colares

“A VIDA COMO ELA É": COMPORTAMENTO ESTRATÉGICO NAS CORTES Patrícia Perrone Campos Mello

A COMPOSIÇÃo do ÓRGão COLEGIAdo E SEUS EFEITOS NA TOMADA DE DECISÃo .720 André Garcia Leão Reis Valadares

Das 11 ilhas ao centro do arquipélago: os superpoderes do Presidente do STF DURANTE O RECESSO JUDICIAL E FÉRIAS .741 José Mário Wanderley Gomes Neto e Flávia Danielle Santiago Lima 
RAZÃo, EMOÇÃo E DELIBERAÇÃO: AS ADEQUAÇÕES REgIMENTAIS do SUPERIOR TribUNAL DE JUSTIÇA PARA A FORMAÇÃo DE PRECEDENTES EFICAZES

Peter Panutto e Lana Olivi Chaim

Heurística de ancoragem e fiXaÇÃo de danos morais em JUizados especiais Cíveis no Rio DE JANEIRO: UMA NOVA ANÁLISE 778

Fernando Leal e Leandro Molhano Ribeiro

LA PROTECCIÓN DE LOS DERECHOS POLÍTICOS FRENTE A LAS FUNCIONES DISCIPLINARIAS DE LAS AUTORIDADES ADMINISTRATIVAS: SUBSIDIARIEDAD Y DEFERENCIA EN EL SISTEMA INTERAMERICANO DE DERECHOS HUMANOS Jorge Ernesto Roa Roa

V. A influênCia do gÊNERo no PROCESSO DECisório JUdiCial

Como os Juízes decidem os Casos de estupro? ANALISANDo SENTENÇAS SOb A PERSPECTIVA DE VIESES E ESTEREÓTIPOS DE GÊNERO 826 Gabriela Perissinotto de Almeida e Sérgio Nojiri

GÊNERO E COMPORTAMENTO JUDICIAL NO SUPREMO TRIBUNAL FEDERAL: OS MINISTROS CONFIAM MENOS EM RELATORAS MULHERES?

Juliana Cesario Alvim Gomes, Rafaela Nogueira e Diego Werneck Arguelhes

Hércules, Hermes e a Pequena Sereia: uma reflexão sobre estereótipos de gênero, SUBPRESENTAÇÃo DAS MULHERES NOS TRIBUNAIS E (I)LEGITIMIDADE DEMOCRÁTICA DO PODER JUDICIÁRIO. .878 Jane Reis Gonçalves Pereira e Renan Medeiros de Oliveira

Prisão Cautelar de gestantes: análise do Fundamento filosófico da decisão do Habeas CoRpus N. 143.641 912

Artur César Souza e Giovania Tatibana de Souza

VI. Neurodireito APlicado ao direito E Ao Processo PENAL....................................926

CÉREbros QUe PUNEM: UMA REVISÃo CRÍTICA DA NEURoCIÊNCIA DA PUNIÇÃo .....................928 Ricardo de Lins e Horta

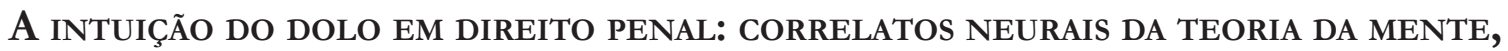
RACIOCÍNIO INDUTIVO E A GARANTIA DA CONVICÇÃO JUSTIFICADA. .946 Thiago Dias de Matos Diniz e Renato César Cardoso

As COMUNIDADES EPISTÊMICAS PENAIS E A PRODUÇÃo LEGISLATIVA EM MATÉRIA CRIMINAL..... 961 Stéphane Enguéléguélé 
DELINQUÊNCIA JUVENIL: RELAÇÕES ENTRE DESENVOLVIMENTO, FUNÇÕES EXECUTIVAS E COMPORTAMENTO SOCIAL NA ADOLESCÊNCIA .

André Vilela Komatsu, Rafaelle CS Costa e Marina Rezende Bazon

Límites TEMPORALES A LAS PENAS PRIVATIVAS DE LIBERTAD ATENDIENDO AL DESARROLLO PSICOSOCIAL.

Silvio Cuneo Nash

NEURolaw E AS PERSPECTIVAS PARA UMA ANÁLISE OBJETIVA DO COMPORTAMENTO SUGESTIONADO: REPERCUSSÃO DAS FALSAS MEMÓRIAS NA ESFERA PENAL

Mariana Dionísio de Andrade, Marina Andrade Cartaxo e Rafael Gonçalves Mota

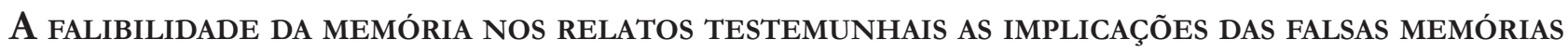
NO CONTEXTO DOS CRIMES CONTRA A DIGNIDADE SEXUAL

Caroline Navas Viana

A (IR)REPETIBILIDADE dA PROVA PENAL DEPENDENTE DA MEMÓRIA: UMA DisCUSSÃo COM BASE NA PSICOLOGIA DO TESTEMUNHO. 1058

William Weber Cecconello, Gustavo Noronha de Avila e Lilian Milnitsky Stein 


\section{Nudges e políticas públicas: um mecanismo de combate ao trabalho em condição análoga à de escravo*}

\author{
Nudges and public policies: a mechanism to \\ fight labor in conditions analogous to slavery
}

\author{
Amanda Carolina Souza Silva** \\ Débhora Renata Nunes Rodrigues*** \\ Saul Duarte Tibaldi****
}

* Recebido em 31/05/2018

Aprovado em 29/06/2018

** Mestranda do Programa de Pós-graduação em Direito da Universidade Federal de Mato Grosso (UFMT). Graduada em Direito pela Universidade do Estado de Mato Grosso (UNEMAT). Graduada em Psicologia pela Faculdade do Pantanal (FAPAN). Especialista em Direito Penal pela Faculdade Damásio de Jesus. Membra do Grupo de Pesquisa Direito do Trabalho Contemporâneo da Faculdade de Direito da UFMT. Bolsista da Capes. E-mail: amandacarolinaadv@gmail.com

*** Mestranda do Programa de Pós-graduação em Direito da Universidade Federal de Mato Grosso (UFMT). Advogada. Membra do Grupo de Pesquisa O meio ambiente do trabalho equilibrado como componente do trabalho decente - GPMAT/UFMT. Graduada em direito pela Universidade Federal de Mato Grosso. E-mail: debhorarenato@hotmail.com

**** Doutor e Mestre em Direito pela Pontifícia Universidade Católica de São Paulo (PUC-SP). Professor nos cursos de Graduação e Mestrado e Diretor da Faculdade de Direito da Universidade Federal de Mato Grosso (UFMT).E-mail: sauldt@ig.com.br

\section{Resumo}

O objetivo deste artigo é analisar como e em que medida os nudges, ou os estímulos de comportamento, adotados pelo Estado por meio de políticas públicas, podem conduzir a uma forma mais eficaz de prevenção e combate ao trabalho em condição análoga à de escravo no Brasil. Para tanto, busca-se, mediante pesquisa bibliográfica e documental e utilização do método dedutivo, tratar da Teoria dos Sistemas, com base em Niklas Luhmann, e examinar o uso de nudges com base em políticas públicas. Posteriormente, aborda-se a relação da dignidade da pessoa humana com o trabalho, apresenta-se o conceito de trabalho decente e uma breve contextualização do trabalho escravo contemporâneo. Por fim, tenta-se verificar os reflexos dos nudges estatais, que, para fins deste estudo, se limitam à Lei no 14.946/2013 (Lei Bezerra) e à "lista suja", no comportamento e atuação das empresas no que concerne ao cumprimento das leis trabalhistas. A pesquisa possibilitou constatar que, além dos nudges de combate ao trabalho escravo contemporâneo terem potencial de serem maximizados, a formulação e a implementação de políticas baseadas no nudge como um incentivo, por meio de benefícios advindos da observância das normas trabalhistas e, portanto, da promoção do trabalho decente, propiciaria, mais eficácia do que apenas a prática condenatória. A hipótese desenvolvida no presente estudo implica considerar, de modo consequente, a análise das questões sociais, baseada numa ótica de transversalidade entre as áreas de conhecimentos, na busca da compreensão do problema, a partir da sua complexidade.

Palavras-chave: Nudges. Políticas públicas. Trabalho em condição análoga à de escravo.

\section{Abstract}

The purpose of this article is to analyze how and to what extent nudges, or behavioral stimuli, adopted by the State through public policies, can lead to a more effective prevention and fight against labor in a condition analogous to slavery in Brazil. In order to do this, we search through bibliographic 
and documentary research and use of the deductive method, to deal with systems theory based on Niklas Luhmann and to examine the use of nudges from public policies. Subsequently, the relation between the dignity of the human person and the work is presented, the concept of decent work is presented and a brief contextualization of contemporary slave labor. Finally, we try to verify the reflexes of the state nudges, which for the purposes of this study are limited, Law 14.946 / 2013 (Lei Bezerra) and the "dirty list", in the behavior and performance of companies regarding compliance of labor laws. The research made it possible to verify that besides nudges to combat contemporary slave labor have the potential to be maximized, the formulation and implementation of policies based on nudge as an incentive, through benefits derived from observance of labor standards and, therefore, promotion of decent work, would be more effective than condemnatory practice. The hypothesis developed in the present study implies considering, in a consequent way, the analysis of social issues, based on a perspective of transversality between the areas of knowledge, in the search for understanding, the problem from its complexity.

Keywords: Nudges. Public policy. Working in a condition analogous to slavery.

\section{INTRODUÇÃo}

Um olhar transdisciplinar baseado na abordagem econômica tradicional e na psicologia comportamental revelou que, por trás do processo de tomada de decisões, dos indivíduos podem existir fatores e aspectos latentes ou não detectáveis a nível consciente que efetivamente influenciam nas mais diversas escolhas, individuais e/ou sociais constantes nas vidas das pessoas. Hábitos, experiências pessoais, interesses, necessidades, desejos e emoções, engendram o complexo mosaico do processo decisório.

A arquitetura das escolhas ou nudge implica uma intervenção no desenho de organização de possibilidades de escolha de uma pessoa, que estimula um determinado comportamento, sem, contudo, restringir a liberdade de decisão desta. A proposta de um nudge pode ser concebida de forma privada a fim de se ter alcance individual e/ ou coletivo ou, ainda, por meio de ações governamentais ou políticas públicas para se estimular condutas positivas ou negativas, da sociedade ou de um determinado segmento social específico ou mais genérico.

As políticas públicas podem ser compreendidas como um conjunto de projetos, programas e atividades realizadas pelo governo em nível nacional, regional ou municipal, a fim de se alcançarem determinados objetivos a longo prazo, que concernem sobretudo à efetivação de direitos fundamentais, dos quais se destacam os direitos sociais.

O Estado Brasileiro, por meio de diversos documentos internacionais, se comprometeu a combater a degradação humana, mediante a proibição da escravidão e da servidão, e também a alcançar o emprego pleno e produtivo e o trabalho decente, por meio da adoção de todas as medidas, legislativas e de outras naturezas que sejam viáveis e necessárias a tal intento.

Submeter alguém a trabalho em condição análoga à de escravo é conduta vedada pelo ordenamento jurídico doméstico, com consequência nas esferas penal, civil, administrativa e trabalhista. Verifica-se que um dos fatores mais preponderantes e que evidenciam a insistente recorribilidade dessa prática nefasta é o arcaísmo das relações produtivas, ainda predominante em determinadas regiões do país. Fator que demonstra uma situação em que o Estado, mesmo munido de distintos instrumentos, de repressão e combate ao trabalho análogo à escravidão, não consegue sanar.

Levando-se em consideração a análise das questões sociais e jurídicas sob uma ótica transdisciplinar e o uso de nudges na abordagem das políticas públicas de prevenção e combate a uma prática social complexa e perversa que afronta a dignidade da pessoa humana, como o trabalho análogo à condição de escravo, busca-se discutir os reflexos desse tipo de intervenção no combate ao trabalho escravo contemporâneo por meio da Lei n’ 14.946/2013 (Lei Bezerra) e da "lista suja". 
A escolha de abordar a Lei Bezerra e o Cadastro de Empregadores que tenham mantido trabalhadores em condições análogas à de escravo se deu em razão da verificação de que essas referidas políticas públicas, uma de âmbito nacional (lista suja) e outra de âmbito estadual (Lei Bezerra), podem ser consideradas como autênticos nudges, na medida em que possuem um aspecto preponderante que denota uma abordagem de incentivo, e não apenas de caráter sancionatório, para que sejam observadas as normas trabalhistas.

Sendo assim, objetivou-se neste trabalho investigar como, e em que medida, os nudges, ou os estímulos de comportamento, adotados pelo Estado por meio de políticas públicas podem conduzir a uma forma mais eficaz de prevenção e combate ao trabalho escravo contemporâneo no Brasil.

Com o objetivo aludido, este trabalho se valerá, essencialmente, da pesquisa bibliográfica e documental com base na utilização do método dedutivo. O artigo está divido em três seções. Inicialmente, serão tecidas algumas considerações sobre a teoria dos sistemas baseada em Niklas Luhmann, de modo a verificar a possibilidade - e necessidade — de transversalidade entre as áreas de conhecimento, mormente levando em consideração o uso de nudges, na elaboração e implementação de políticas públicas. Em seguida busca-se apontar a relação da dignidade da pessoa humana com o direito ao trabalho decente, de modo a conceituá-lo e apresentá-lo como o oposto ao trabalho em condição análoga à de escravo, que representa uma afronta àquele.

Por fim, na terceira seção, verificam-se os reflexos dos nudges, criados por mecanismos públicos — que para fins deste estudo se limitam a Lei n 14.946/2013 (Lei Bezerra) e a "lista suja" (ou cadastro público de empregadores que submeteram trabalhadores a condições análogas à de escravo), — no comportamento e atuação das empresas no que concerne ao cumprimento das leis trabalhistas, bem como discorre-se, brevemente, se as políticas públicas pautadas em incentivos decorrentes da observância das normas trabalhistas poderiam ser maximizadas, de modo a principiar a proteção ao trabalhador.

Busca-se como resultado do presente estudo possibilitar uma melhor reflexão sobre o tema, com base na necessidade da transversalidade entre as áreas de conhecimento, e a superação do pensamento mecanicista cartesiano de que o direito basta para resolver os problemas sociais.

\section{TEORIA DOS SISTEMAS E NUDGES}

Para que se consiga analisar, numa visão ampla, a possibilidade do uso de nudges por meio de políticas públicas, é imprescindível o conhecimento prévio de alguns aspectos da teoria que sustenta a transversalidade entre as áreas de conhecimento, como será demonstrado adiante.

\subsection{Breve introdução à teoria dos sistemas de Niklas Luhmann}

Preliminarmente faz-se mister elucidar que o pensamento sistêmico, enquanto procedimento científico, surge contrapondo-se aos métodos científicos clássicos embasados na filosofia mecanicista cartesiana. $\mathrm{O}$ pensamento cartesiano (que influenciou diversos ramos do conhecimento), em síntese, propugnava, a partir de uma supervalorização da razão, a busca por uma verdade incontestável, identificada por meio de uma dúvida, e verificada por meio do método analítico, que pesquisava seu objeto por meio de uma dimensão individualizada, dissociada de seu contexto. ${ }^{1}$

Sob o influxo de vigorosas críticas em relação ao pensamento mecanicista, dentre as quais se destacava a fragilidade de estudos satisfatórios do objeto de pesquisa isolado de seu contorno, e da necessidade de

1 MENEGAZZI, Piero Rosa. A efetivação do direito à informação no meio ambiente de trabalho: contribuições do pensamento sistêmico, da teoria da complexidade e do estudo dos riscos. São Paulo: LTr, 2011. p. 63-64. 
superação desta, entre outras deficiências, surge o pensamento sistêmico, que trabalha com a concepção de que o todo apresenta características não encontradas nas partes que o integram. ${ }^{2}$ Para Menegazzi “o sistema é avesso às divisões analíticas provindas do método cartesiano, sendo que o comportamento do todo não pode ser entendido totalmente com a observância do comportamento de suas partes isoladas"3.

A partir da valorização da ótica sistêmica, até houve a tentativa de formulação de uma teoria geral dos sistemas, com a elaboração de conceitos e noções que seriam válidos para qualquer sistema, independentemente da natureza de seus integrantes e das relações entre estes, ${ }^{4}$ mas, atualmente, pode-se afirmar que não existe propriamente uma teoria geral dos sistemas.

$\mathrm{Na}$ área da sociologia, o sociólogo alemão Niklas Luhmann propõe uma teoria dos sistemas. Esse autor interpreta a sociedade como formada por vários sistemas (série de eventos relacionados um ao outro, ou de operações), sociais comunicativos que geram condições próprias para si e, também, para os outros sistemas ao redor. O sistema é composto por elementos (unidade indecomponível) e pela relação (estrutura). ${ }^{5}$

Seu objeto de estudo é analisado com base no pensamento sistêmico e de uma abordagem transdisciplinar. Ele desenvolve uma teoria que tem como principais influências a teoria de sistemas sociais de Parsons, a fenomenologia de Husserl, a segunda ordem da cibernética de Heinz e Foerters e o conceito de autopoiesis da biologia desenvolvida por Maturana e Varela; bem como o cálculo de distinção de Spencer Brown ${ }^{6}$.

O sistema teórico da teoria dos sistemas aloca para o interior das ciências sociais conceitos da biologia, como já citado, da psicologia, da economia, da Teoria da Comunicação, da cibernética, utilizando-os no estudo dos fenômenos sociais.

Luhmann classifica, a partir da abordagem sistêmica, três tipos de sistemas: biológicos, psíquicos e sociais. Os modos de operação e reprodução de cada um deles implicam, respectivamente, para a vida, a consciência e a comunicação ${ }^{7}$. O que revela qualquer um desses sistemas não possui, de forma isolada, condão de compreender o mundo e suas interfaces. Cada sistema compreende a si próprio. A Teoria dos Sistemas Sociais tem como principal fator em comum o fato de sua operação básica ser a comunicação.

A Teoria dos Sistemas toma como ponto inicial um princípio de diferenciação. Luhmann elucida que "o sistema não é meramente uma unidade, mas uma diferença". ${ }^{8}$ A diferenciação do sistema não significa a decomposição de um todo em partes, mas da diferenciação de diferenças sistema/entorno. ${ }^{9}$

Faz-se mister a ilustração da concepção de autopoiesis, que para Luhmann "significa que o sistema se produz a si mesmo, além de suas estruturas". ${ }^{10}$ Isto significa que um sistema, qualquer que seja, autoproduz-se e se autocompleta, retirando de seus próprios elementos os meios necessários para evoluir. $\mathrm{O}$ autor ainda destaca que um sistema autopoiético produz as operações necessárias para realizar mais operações, servindo-se da rede de suas próprias operações, sem jamais suprimir a si próprio.

2 MENEGAZZI, Piero Rosa. A efetivação do direito à informação no meio ambiente de trabalbo: contribuições do pensamento sistêmico, da teoria da complexidade e do estudo dos riscos. São Paulo: LTr, 2011. p. 66.

3 MENEGAZZI, Piero Rosa. A efetivação do direito à informação no meio ambiente de trabalbo: contribuições do pensamento sistêmico, da teoria da complexidade e do estudo dos riscos. São Paulo: LTr, 2011. p. 67.

4 MENEGAZZI, Piero Rosa. A efetivação do direito à informação no meio ambiente de trabalho: contribuições do pensamento sistêmico, da teoria da complexidade e do estudo dos riscos. São Paulo: LTr, 2011. p. 68-69.

5 LUHMANN, Niklas. Introdução à teoria dos sistemas. 3. ed. Petrópolis: Vozes, 2011.

6 SEIDL, D.; BECKER, K. H. Organizations as Distinction Generating and Processing Systems: Niklas Luhmann's Contribution to Organization Studies. Organizations. Sage Journal, v. 13, n. 1, p. 9-35, 2006. Disponível em: <http://journals.sagepub.com/doi/ pdf/10.1177/1350508406059635>. Acesso em: 9 maio 2018.

7 BARONE, Fernando. Sociedade e escola: Niklas Luhmann e a abordagem sistêmica. Ponto e vírgula - Revista das Ciências Sociais, São Paulo, n. 12, p. 5-32, 2013. Disponível em: <https://revistas.pucsp.br/index.php/pontoevirgula/article/viewFile/12678/12310>. Acesso em: 20 maio 2018.

8 LUHMANN, Niklas. Introdução à teoria dos sistemas. 3. ed. Petrópolis: Vozes, 2011. p. 101.

9 KUNZLER, Caroline de Morais. A teoria dos sistemas de Nicklan Luhmann. Estudos de Sociologia, Araraquara, v. 16, p. 123-136, 2004. Disponível em: <https://periodicos.fclar.unesp.br/estudos/article/viewFile/146/144>. Acesso em: 20 maio 2018 . p.123.

10 LUHMANN, Niklas. Introdução à teoria dos sistemas. 3. ed. Petrópolis: Vozes, 2011. p. 113. 
O sistema não tem uma estrutura imutável que enfrenta um ambiente complexo. É condição para esse enfrentamento que o próprio sistema transforme-se internamente, criando subsistemas, deixando de ser simples e tornando-se mais complexo, ou seja, evoluindo. Cada um desses subsistemas criados dentro do sistema tem o seu próprio entorno ${ }^{11}$.

Pela Teoria Sistêmica de Luhmann, o direito é um sistema funcionalmente diferenciado da sociedade, cuja função é manter estável as expectativas, ainda que estas sejam frustradas na prática. Essas expectativas são as normas jurídicas, que, assim, permanecem estáveis independentemente de uma eventual violação ${ }^{12}$.

Para o referido autor, o direito, por meio do seu sistema jurídico, faz emergir subsistemas internamente distintos, subsistemas estes que se conectam com outros sistemas (relacionados muitas vezes a outras áreas do saber). O direito, na medida em que reconhece, produz e soluciona conflitos pode ser considerado, levando em consideração a complexidade de sua estrutura, como normativamente fechado e cognitivamente aberto (na medida em que é estimulado pelo próprio ambiente).

Outra concepção que merece destaque quanto à Teoria dos Sistemas é a comunicação. Considerada como o limite da sociedade, a ela é atribuído o papel de reprodução do sistema social. Para o presente trabalho, faz-se imprescindível mencionar a comunicação jurídica, a qual, segundo Andaku, existe toda vez que, havendo controvérsia, alguém reivindique seus direitos e, com isso, a normatividade vigente deve decidir quem possui a razão pelo código da licitude. Nesse sentido, denota-se que o direito é um sistema que resolve os conflitos, mas, ao mesmo tempo, cria outros mediante sua estrutura interna no processo de autopoieses. ${ }^{13}$

Partindo dessas considerações sobre concepções bases da Teoria dos Sistemas, que não se propôs a tecer toda a complexidade do desenho da Teoria de Luhmann, verificar-se-á a transdisciplinaridade entre as áreas das ciências.

\subsubsection{A economia comportamental e o direito}

Com base na Teoria dos Sistemas, vem se verificando, nos estudos científicos, uma tendência de atuação transdisciplinar entre as áreas do conhecimento. Uma nova ótica que vem permite uma melhor compreensão da realidade social e a elaboração de instrumentos políticos que possibilitam resultados mais efetivos para a sociedade.

Para aclarar melhor essa transdisciplinaridade, pode-se verificar a interface entre direito e economia, que possibilitou a gênese da Análise Econômica do Direito (AED), considerada uma área emergente do direito que pressupõe a aplicação da Teoria Econômica para analisar institutos jurídicos e políticas públicas.

A análise econômica do direito parte da premissa de que as pessoas são racionais e reagem aos incentivos a que estão sujeitas. Analisam custos de transação para realizar seus próximos passos; de modo que tomam decisões de acordo com os custos e benefícios. Essa escolha racional pode ser compreendida como a ponderação, uma análise cuidadosa das vantagens e dos respectivos custos, quando o indivíduo exercita a tomada de decisão.

Para Tabak "a existência de custos de transação relevantes podem levar a economia a ficar aquém do seu potencial - revelando ineficiências importantes que, na ausência desses custos, poderiam ser eliminadas”. Essa lógica econômica acaba sendo aplicada quando se trata de direitos trabalhistas. Levando em consideração e relacionando o problema jurídico em questão, percebe-se que muitas empresas, ainda, consideram

11 KUNZLER, Caroline de Morais. A teoria dos sistemas de Nicklan Luhmann. Estudos de Sociologia, Araraquara, v. 16, p. 123-136, 2004. Disponível em: <https://periodicos.fclar.unesp.br/estudos/article/viewFile/146/144>. Acesso em: 20 maio 2018 . p. 125.

12 ANDAKU, Juliana Almenara. O direito na teoria de Niklas Lubmann. Disponível em: <www.agu.gov.br/page/download/index/ id/692917>. Acesso em: 21 maio 2018.

13 ANDAKU, Juliana Almenara. O direito na teoria de Niklas Lubmann. Disponível em: <www.agu.gov.br/page/download/index/ id/692917>. Acesso em: 21 maio 2018. 
o custo-benefício do trabalho análogo ao escravo mais viável e/ou rentável que o cumprimento das leis trabalhistas. Acreditam que o cumprimento dessas leis as deixariam aquém do seu melhor potencial de lucro. As reiteradas escolhas de menores custos e maiores benefícios possíveis trouxe muitas mudanças na organização produtiva do mundo do trabalho e uma consequência nefasta para os direitos trabalhistas: o dumping social.

Contrariamente a análise econômica do direito, a Análise Econômica Comportamental do Direito considera que os indivíduos não tomam decisões baseados, exclusivamente, na racionalidade, mas em aspectos que às vezes podem fazer com que tomem escolhas contrárias aos seus interesses e até mesmo ao seu próprio bem-estar. Essa abordagem demonstra que há mecanismos emocionais e cognitivos, muitas vezes inconscientemente, que estão por trás das escolhas e decisões das pessoas.

A análise econômica comportamental pode ser compreendida como a disciplina "que busca seus fundamentos principalmente na área da Psicologia tentando explicar a motivação dos fenômenos que causam um desvio da atitude humana esperada, considerando-se o ser humano como um ser racional”"14.

Diferentemente da perspectiva de racionalidade exacerbada da análise econômica do direito, a Economia Comportamental enxerga uma realidade formada por pessoas que decidem com base em hábitos, experiências pessoais e regras práticas simplificadas. Aceitam soluções, apenas, satisfatórias, tomam decisões rapidamente e têm dificuldade de conciliar interesses de curto e longo prazo; além disso, são fortemente influenciadas por fatores emocionais e pelas decisões daqueles com os quais interagem ${ }^{15}$.

Com base em tais pressupostos, destaca-se que a análise econômica comportamental do direito tem evoluído na Teoria da Arquitetura das Escolhas (que é um instituto próprio da análise econômica comportamental do direito), conforme será verificado no item 3.1. Entes privados e o próprio Estado, ambos cientes que vieses, comportamentos e ambiente impactam as escolhas dos indivíduos, melhoram a disposição das escolhas para possibilitarem mais chances da tomada de decisões favoráveis aos interesses das pessoas ou aos seus próprios interesses.

A análise econômica comportamental do direito tem exercido na atualidade um papel basilar quanto à formulação e implementação de políticas públicas — que, por razão dos fins desta pesquisa, se limitam à Lei n 14.946/2013 (Lei Bezerra) e à "lista suja" - se configurando como uma das principais áreas da ciência, responsável pela criação e adoção de novas leis que leva em conta a racionalidade limitada ou "enviesada" das pessoas ${ }^{16}$, possibilitando a elas a realização de escolhas melhores, que maximizem sua utilidade, de forma menos invasiva. ${ }^{17}$

Antes o exposto, denota-se que a criação e a implementação de políticas públicas com mais possibilidade de eficácia não podem ser guiadas por uma análise que desconsidere os fundamentos e as ferramentas fornecidas pela transversalidade entre a Econômica Comportamental e o Direito.

14 SCALEA, José Augusto; TABAK, Benjamin Miranda. Direito de propriedade intelectual: formas de proteção, seu impacto no desenvolvimento econômico e propostas para sua melhoria. Revista de Direito Econômico e Socioambiental, Curitiba, v. 7, n. 2, p. 154174, jul./dez. 2016. Disponível em: <https://periodicos.pucpr.br/index.php/direitoeconomico/article/view/5837>. Acesso em: 30 abr. 2018. p. 157.

15 SANSON apud ÁVILA, Flávia; BIANCHI, Ana Maria. Guia de economia comportamental e experimental. São Paulo: economia comportamental.org., 2015. p. 14.

16 SCALEA, José Augusto; TABAK, Benjamin Miranda. Direito de propriedade intelectual: formas de proteção, seu impacto no desenvolvimento econômico e propostas para sua melhoria. Revista de Direito Econômico e Socioambiental, Curitiba, v. 7, n. 2, p. 154174, jul./dez. 2016. Disponível em: <https://periodicos.pucpr.br/index.php/direitoeconomico/article/view/5837>. Acesso em: 30 abr. 2018.

17 O paternalismo libertário é o ponto médio entre o liberalismo (que propõe a intervenção mínima do Estado) e o paternalismo coercitivo. Mantém a possibilidade de escolhas, mas incentiva a escolha adequada. O Estado dá um empurrão (nudge) para a escolha certa. THALER, Richard H; SUNSTEIN, Cass R. Nudge: o empurrão para a escolha certa: aprimore suas decisões sobre saúde, riqueza e felicidade. Rio de Janeiro: Elsevier, 2009. 


\subsection{Nudges, arquitetura de escolhas e políticas públicas}

Pôde-se verificar que é possível utilizar a Teoria Econômica e a Comportamental não apenas para analisar institutos jurídicos e políticas públicas, mas também para aumentar a eficiência de comportamentos que deveriam ser adotados por indivíduos, pela sociedade ou um determinado segmento social. Esse item do presente estudo busca verificar como os mecanismos públicos podem dirigir comportamentos a fim de se influenciar as escolhas e obter resultados desejáveis (sob o prisma dos governos).

\subsubsection{Nudges e a arquitetura das escolhas}

Nos últimos anos, o termo "arquitetura das escolhas", cunhado por Richard h. Thaler e Cass R. Sunstein, na obra Nudge: Improving Decisions about Health, Wealth and Happiness (2008), tornou-se comum em várias áreas das ciências. Um olhar transdisciplinar baseado na abordagem econômica tradicional e na psicologia comportamental revelou que, por trás do processo de tomada de decisões das pessoas, existem fatores e aspectos latentes ou não detectáveis a nível consciente que, efetivamente, decidem as escolhas destas, ainda que essas escolhas caminhem ao desencontro dos seus próprios interesses.

A arquitetura das escolhas ou nudge é uma teoria que pode ser conceituada como uma intervenção no desenho de organização de possibilidades de escolha de uma pessoa, que estimula um determinado comportamento, sem, contudo, restringir a liberdade de decisão desta.

Os proponentes dessa teoria pregam sua aplicabilidade nas mais diversas situações da vida. Um nudge pode ser produzido, de forma privada, a fim de se ter alcance individual e/ou coletivo ou, ainda, por meio de mecanismos públicos ou políticas públicas para se estimular condutas positivas ou negativas da sociedade ou de um determinado segmento social.

Nudge é uma palavra da Língua Inglesa que, segundo o Cambridge dictionary ${ }^{18}$, significa empurrar ou cutucar. Sustein ${ }^{19}$ define nudge como uma intervenção que preserva a liberdade de escolha, ainda que possa influenciar a tomada de decisão ${ }^{20}$. Ambrosino, et al. entendem que o nudge "refere-se à ideia que o comportamento das pessoas pode ser suave ou gentilmente empurrado para um certo curso de ação" 21 . O nudge não visa coagir, mas induzir, influenciar a tomada de decisão.

As escolhas que os seres humanos tomam não são totalmente livres: alguém ou algo está, de alguma forma, influenciando as decisões que são tomadas por cada pessoa ${ }^{22}$. Ademais, todos em maior ou menor proporção realizam escolhas diariamente, sobre uma infinidade de fatos que variam em grau de complexidade. Escolhe-se desde a roupa que se vestirá ao alimento que será ingerido e, independentemente de nossas decisões, sempre sofreremos as consequências de nossas escolhas.

Ocorre, todavia, que podemos escolher de forma equivocada. Levando em consideração que não escolhemos somente com base na racionalidade. A economia comportamental adota como premissa a tese de que o ser humano é conduzido por dois sistemas: o primeiro deles é automático, responsável pelas avalia-

18 CAMBRIDGE INTERNATIONAL. Dictionary of English. New York: CUP, 2000.

19 THALER, Richard H.; SUNSTEIN, Cass R. Nudge: o empurrão para a escolha certa: aprimore suas decisões sobre saúde, riqueza e felicidade. Rio de Janeiro: Elsevier, 2009. Disseminou o conceito de que o comportamento das pessoas pode ser influenciado por incentivos.

20 SUNSTEIN, Cass R. Nudging: a very short guide. p. 1. Disponível em: < https://papers.ssrn.com/sol3/papers.cfm?abstract_ id $=2499658>$. Acesso em: 29 abr. 2018.

21 AMBrosinO, A. Faralla V.; NOVARESE, M. Nudge: a critical perspective. In: MARCIANO, A.; RAMELLO, G. (Eds.). Enciclopédia de Direito e Economia. New York: Springer, 2018. Disponível em: <https://doi.org/10.1007/978-1-4614-7883-6_631-1>. Acesso em: 30 abr. 2018.

22 FRANCO, Claudia Regina Lovato; TABAK, Benjamim Miranda; BIJOS, Leila. A lei no 14.946/2013 (lei bezerra): um nudge para incentivar empresários do setor de confecção da indústria paulista a cumprirem as leis trabalhistas. Revista de Direito Brasileira, São Paulo, v. 16, n. 7, p. 346-362, jan./abr. 2017. p.354 
ções básicas e intuitivas; e o segundo é reflexivo e intencional responsável pelas construções mentais mais elaboradas e demoradas. Thaler e Sunstein elucidam:

Uma maneira de pensar sobre tudo isso é a de que o Sistema automático é a sua reação instintiva, enquanto o Sistema reflexivo é seu pensamento consciente. Os impulsos instintivos podem ser bastante precisos, mas muita vezes cometemos erros porque confiamos demais em nosso sistema automático. O sistema automático diz: "O avião está balançando, vou morrer", enquanto o sistema reflexivo reage: "Aviões são muito seguros!"’33

O ser humano acaba utilizando muito mais o sistema automático e isso interfere, indubitavelmente, na qualidade de suas escolhas. Partindo-se dessas considerações, Thaler e Sunsteim desenvolvem a Teoria da Arquitetura das Escolhas ou nudging, que defende que é possível a organização do contexto no qual as pessoas tomam decisões, com objetivo de influenciá-las de forma previsível pela ciência.

A partir do exame das escolhas, levando-se em consideração um estudo holístico de perspectivas e da análise de escolhas passadas como uma via produtiva na tomada de decisões com a elaboração da arquitetura das escolhas, é possível ajudar as pessoas a fazerem melhores escolhas, pois não há escolhas totalmente livres: alguém ou algo está, de alguma forma, influenciando as decisões que tomamos ${ }^{24}$.

Mister se faz destacar que os nudges preservam uma margem considerável de liberdade de escolha, seja elaborado de forma privada ou por entes governamentais. Todavia quando se trata de mecanismos públicos, qualquer cutucada oficial (nudge) deve ser transparente e aberta em vez de oculta e encoberta. A transparência deve ser sempre incorporada à prática básica ${ }^{25}$.

Partindo-se dessas considerações e das contribuições da análise econômica comportamental do direito, mormente no que concerne ao estudo dos fatores que influenciam as escolhas e as decisões das pessoas, verificar-se-á como os nudges podem ser elaborados sob o prisma governamental.

\subsubsection{Nudges e políticas públicas}

O Estado pode formular nudges, ou estímulos de comportamento por meio da elaboração de leis, políticas públicas ou outras medidas governamentais. As políticas públicas podem ser compreendidas com base em duas vertentes: uma que encara a política pública como um processo de decisão em que há conflito de interesses e outra que decorre do ponto de vista administrativo, ou seja, que entende as políticas públicas como conjunto de projetos, programas e atividades realizadas pelo governo em nível nacional, regional ou municipal a fim de se alcançar determinados objetivos em longo prazo ${ }^{26}$.Essa pesquisa aborda as políticas públicas a partir da segunda vertente..$^{27}$

Brancaleon, et al. explicam que a política pública possui dois elementos fundamentais: a) Intencionalidade pública, ou seja, a motivação para o estabelecimento de ações para tratamento ou para resolução de

23 THALER, Richard H; SUNSTEIN, Cass R. Nudge: o empurrão para a escolha certa: aprimore suas decisões sobre saúde, riqueza e felicidade. Rio de Janeiro: Elsevier, 2009. p. 23.

24 FRANCO, Claudia Regina Lovato; TABAK, Benjamim Miranda; BIJOS, Leila. A lei no 14.946/2013 (lei bezerra): um nudge para incentivar empresários do setor de confecção da indústria paulista a cumprirem as leis trabalhistas. Revista de Direito Brasileira, São Paulo, v. 16, n. 7, p. 346-362, jan./abr. 2017. p.354.

25 SUNSTEIN, Cass R. Nudging: a very short guide. p. 2. Disponível em: < https://papers.ssrn.com/sol3/papers.cfm?abstract_ id $=2499658>$. Acesso em: 29 abr. 2018.

26 BRANCALEON, Brigida Batista et. al. Políticas públicas: conceitos básicos. São Paulo: Universidade de São Paulo, 2015.

27 Neste mesmo sentido discorre Bruno Santos Cunha, para quem o termo políticas públicas deve ser utilizado como programa de ação governamental consistente em um conjunto estruturado de normas e atos com finalidade predeterminada. Disso decorre a necessidade de se pensar, cada vez mais, o horizonte jurídico atrelado à esfera política, traçando laços entre tais patamares que ensejem a criação e formatação de um subsistema que verdadeiramente possa administrar a implementação das referidas políticas de acordo com os ditames teórico-constitucionais. CUNHA, Bruno Santos. Direitos fundamentais: da constituição às políticas públicas. Rev. Bras. Políticas Públicas, Brasília, v. 1, n. 1, p. 65-82, jan./jun. 2011. p. 72. 
um problema; b) Problema público ${ }^{28}$. Isso denota que a motivação da elaboração da política pública não precisa ter gênese somente no Estado, mas também com base em entidades privadas, desde que tenham interesse em dirimir um problema público. Souza sintetiza, entre diversos modelos sobre políticas públicas, seus principais elementos:

A política pública permite distinguir entre o que o governo pretende fazer e o que, de fato, faz. A política pública envolve vários atores e níveis de decisão, embora seja materializada através dos governos, e não necessariamente se restringe a participantes formais, já que os informais são também importantes. A política pública é abrangente e não se limita a leis e regras. A política pública é uma ação intencional, com objetivos a serem alcançados. A política pública envolve processos subsequentes após sua decisão e proposição, ou seja, implica também implementação, execução e avaliação. ${ }^{29}$

Com isso se percebe que a política pública pode ser compreendida como uma ação multifacetada, com objetivos a longo prazo, que compreendem as fases de formação da agenda, formulação, implementação, execução e avaliação da política. Partindo-se dessas considerações, verificaremos a possibilidade da elaboração de nudges por meio de políticas públicas.

Para Thaler e Sunsteim, a vantagem do nudge em relação a ações mais impositivas ou processos regulatórios é a preservação do máximo da autonomia e da liberdade de escolha das pessoas. Esses autores propuseram, em sua obra conjunta, "Nudge: o empurrão para a escolha certa" um dos principais esforços para incorporar as noções da economia comportamental no processo regulatório - a Teoria do Paternalismo Libertário, que pode ser compreendida como um tipo de intervenção estatal mais leve, menos intrusiva, mas que incentiva comportamentos em determinada direção. Para eles o aspecto libertário se refere à liberdade do sujeito de fazer o que quiser e ter opção de sair de arranjos não desejados se assim o quiser, e o aspecto paternalista consiste na possibilidade que o arquiteto de escolhas tem, de tentar influenciar o comportamento de pessoas, a fim de tornar sua vida mais longa, saudável e melhor ${ }^{30}$. Nesse sentido lecionam:

É verdade que algumas cutucadas são propriamente descritas como uma forma de paternalismo "porque orientam as pessoas em uma determinada direção. Mas mesmo quando é assim, esses toques são especificamente projetados para preservar a total liberdade de escolha. Um, gps, guia uma pessoa em uma determinada direção, mas a pessoa têm a liberdade de selecionar sua própria rota ${ }^{31}$.

Isso significa que é possível que um Estado menos intervencionista possa auxiliar seus cidadãos a realizarem melhores escolhas. Mas ele por si não o faz ${ }^{32}$. Ademais os nudges elaborados pelo Estado, conforme elucida Sunstein,

Devem ser transparentes e abertos ao invés de ocultos e encobertos. De fato, a transparência deve ser incorporada à prática básica. Suponha que um governo (ou um empregador privado) adota um programa que automaticamente registra pessoas em um programa de pensão, ou suponha que uma grande instituição (digamos, uma cadeia de lojas privadas, ou aqueles que dirigem cafeterias em prédios do governo) decide tornar os alimentos saudáveis mais visíveis e acessíveis. Em ambos os casos, a ação relevante não deve ser escondida de qualquer forma. As decisões do governo, em particular, devem ser sujeito ao escrutínio público e revisão. Uma vantagem principal dos toques ou cutucadas, em oposição

28 BRANCALEON, Brigida Batista et. al. Políticas públicas: conceitos básicos. São Paulo: Universidade de São Paulo, 2015. p.2.

29 SOUZA, C. Política Públicas: uma revisão da literatura. Sociologias, Porto Alegre, ano 8, n. 16, p. 20-45, jun./dez. 2006. Disponível em: <http://www.scielo.br/pdf/soc/n16/a03n16>. Acesso em: 15 abr. 2018.

30 THALER, Richard H; SUNSTEIN, Cass R. Nudge: o empurrão para a escolha certa: aprimore suas decisões sobre saúde, riqueza e felicidade. Rio de Janeiro: Elsevier, 2009. p. 5.

31 SUNSTEIN, Cass R. Nudging: a very short guide. p. 2. Disponível em: < https://papers.ssrn.com/sol3/papers.cfm?abstract_ id $=2499658>$. Acesso em: 29 abr. 2018.

32 "O paternalismo libertário é um tipo de paternalismo relativamente fraco, brando e não intrusivo porque as escolhas não são bloqueadas, obstruídas ou significativamente sobrecarregadas. Se as pessoas quiserem fumar, comer um monte de doces ou não poupar, os paternalistas libertários não as forçarão para que mudem de comportamento. No entanto, a abordagem recomendada pelos autores conta como paternalista porque arquitetos de escolhas públicos e privados não estão simplesmente tentando rastrear ou implementar as previsões de escolhas das pessoas. Ao revés, estão conscientemente tentando guiar as pessoas em direções que irão melhorar a vida delas. FERREIRA, Felipe Furtado; POTTUMATI, Eduardo Carlos. A licitação pública como instrumento de desenvolvimento na perspectiva do paternalismo libertário. Rev. Bras. Políticas Públicas, Brasília, v. 4, n. 1, p. 201-215, jan./jun. 2014. p. 213. 
aos mandatos e proibições, é que eles evitam a coerção. ${ }^{33}$

Verifica-se, portanto, que, quando se tratar de um nudge formulado pelo Estado, ele deve ser aplicado com total transparência. Outrossim, quando for esse caso, Sunstein aclara que é extremamente importante confiar nas evidências em vez de intuições, anedotas, pensamentos desejosos ou dogmas. O mais eficaz é que se submeta os nudges a testes empíricos, que reflitam uma compreensão realista de como as pessoas responderão às iniciativas do governo. ${ }^{34}$

Sunstein destaca as cutucadas ou nuddges mais importantes para fins de política: a) regras padrão (por exemplo, inscrição automática em programas, incluindo educação, saúde, poupança); b) simplificação das formas e procedimentos (em parte para promover a aceitação de programas existentes); c) usos de normas sociais (enfatizando o que a maioria das pessoas faz, para reforçar um comportamento desejado); d) aumento da facilidade e conveniência (por exemplo, fazendo opções de baixo custo ou alimentos saudáveis visíveis); e) divulgação (por exemplo, os custos econômicos ou ambientais associados ao uso de energia); f) avisos, gráficos ou outros (como para cigarros); g) estratégias de pré-comprometimento (pelas quais as pessoas se comprometem a certa ação); h) lembretes (por exemplo, por e-mail ou mensagem de texto, como por contas em atraso e próximas obrigações ou nomeações); i) indução de intenções de implementação (por exemplo uma pesquisa que busca investigar: "você planeja votar?" - É mais provável que as pessoas se envolvam em atividades se alguém provocar intenções de implementação) j) informando as pessoas sobre a natureza e consequências de seu próprio passado de escolhas. ${ }^{35}$

Utilizando-se de uma dessas formas de empurrão na arquitetura das escolhas sociais, o Estado pode elaborar vários nudges, que conduzam previnam ou desestimulem determinados comportamentos.

\section{A relaÇão entre O trabalHo E A PROMOÇÃo da dignidade hUMANA}

Nessa seção abordaremos institutos de direito, para que a seguir possamos analisar como e em que medida os nudges, ou os estímulos de comportamento, adotados pelo Estado por meio de políticas públicas podem conduzir a uma forma mais eficaz de prevenção e combate ao trabalho análogo ao escravo no Brasil.

A escravidão, em todas as suas formas, representa o desrespeito a direitos fundamentais e difusos da sociedade, consagrados na Carta Magna, tais como: a proteção à dignidade da pessoa humana (art. $1^{\circ}$, III); os valores sociais do trabalho e da livre iniciativa (artigo $1^{\circ}$, IV); a construção de uma sociedade livre, justa e solidária (art. $3^{\circ}$. I); a inviolabilidade do direito à vida, à liberdade, à igualdade, à segurança (art. $5^{\circ}$, caput); o princípio da legalidade (art. $\left.5^{\circ}, \mathrm{II}\right)$; não submissão à tortura ou a tratamento desumano ou degradante (art. $\left.5^{\circ}, \mathrm{III}\right)$; a inviolabilidade da intimidade, da vida privada, da honra e da imagem (art. 5० $\mathrm{X}$ ); a liberdade de exercício de trabalho, ofício ou profissão (art. $5^{\circ}$, XIII); a liberdade de locomoção (art. $5^{\circ}$, XV); a função social da propriedade (art. $5^{\circ}$, XXIII); a proibição de imposição de pena de trabalhos forçados e cruéis (art. $\left.5^{\circ}, \mathrm{XLVI}\right)$; e a proibição de prisão civil por dívida (art. $5^{\circ}$, LXVII). ${ }^{36}$

Com isso, faz-se necessário explanar a relação da dignidade humana com o trabalho decente, para em seguida demonstrar que a antítese deste é o trabalho em condição análoga à de escravo, crime positivado no Código Penal brasileiro.

33 SUNSTEIN, Cass R. Nudging: a very short guide. p. 4. Disponível em: < https://papers.ssrn.com/sol3/papers.cfm?abstract_ id $=2499658>$. Acesso em: 29 abr. 2018.

34 SUNSTEIN, Cass R. Nudging: a very short guide. p. 5. Disponível em: < https://papers.ssrn.com/sol3/papers.cfm?abstract_ id $=2499658>$. Acesso em: 29 abr. 2018.

35 SUNSTEIN, Cass R. Nudging: a very short guide. p. 3-6. Disponível em: < https://papers.ssrn.com/sol3/papers.cfm?abstract_ id $=2499658>$. Acesso em: 29 abr. 2018.

36 BRASIL. Constituição (1988). Constituição da República Federativa do Brasil. Disponívelem:<http://www.planalto.gov.br/ccivil_03/constituicao/constituicao.htm>. Acesso em: 8 maio 2018. 


\subsection{O direito ao trabalho digno}

Kant afirmou a necessidade de distinção entre coisas que não possuem dignidade, correspondentes àquelas que possuem um preço de modo que podem ser facilmente substituídas por outras, e aquelas que possuem dignidade, ou seja, coisas que estão acima de qualquer preço. Com base nisso, o autor preconizava que a humanidade deveria ser usada sempre "como fim e nunca simplesmente como meio". ${ }^{37}$

Diante das inúmeras transformações ocorridas no decorrer da história, Sarlet propõe uma atualização do clássico conceito de dignidade da pessoa humana, resultando na assertiva de que essa é qualidade inerente de cada pessoa que a faz merecedora de respeito tanto por parte da comunidade quanto do Estado, de maneira a resultar num "complexo de direitos e deveres fundamentais" que garanta o indivíduo contra qualquer ato "degradante e desumano", ou lhe assegure as condições mínimas para uma vida sadia, e ainda na viabilização e promoção da "participação ativa e corresponsável deste nos destinos da própria existência e da vida em comunhão com os demais seres humanos, mediante o devido respeito aos demais seres que integram a rede da vida". ${ }^{38}$

Haja vista a ideia transcrita, já é possível defender que a promoção e proteção da dignidade da pessoa humana requer a observância do direito ao trabalho (e do direito do trabalho). Tal assertiva é corroborada em relação à leitura do artigo 23 da Declaração Universal dos Direitos Humanos de 1948, que deixa positivada a relação versada.

Isso pois, como bem argumenta Miraglia, o trabalho deve ser "instrumento" de promoção da dignidade humana, proporcionando meios para que seja possível a inserção efetiva do trabalhador na "sociedade capitalista" $" 39$.

No âmbito nacional, o explanado possui amparo na Constituição Federal de 1988, que reconhece o direito ao trabalho como jusfundamental em seu artigo $6^{\circ}$, caput, o qual está situado no título II, referente aos direitos fundamentais, que possuem por escopo a promoção e proteção dos fundamentos basilares da República, do Estado Democrático de Direito, qual seja, da dignidade humana, dos valores sociais do trabalho, entre outros, conforme se depreende do artigo $1^{\circ}$ do documento em voga.

Nessa esteira, cumpre ressaltar que, em junho de 1998, a Organização Internacional do Trabalho (OIT) adotou a Declaração de Princípios e Direitos Fundamentais do Trabalho, a qual estabelece, em seu artigo $2^{\circ}$, que todos os membros da OIT, mesmo os que não tenham ratificado convenções específicas, possuem o compromisso de respeitar os princípios relativos aos direitos fundamentais do trabalho, quais sejam: (a) a liberdade sindical e o reconhecimento efetivo do direito de negociação coletiva; (b) a eliminação de todas as formas de trabalho forçado ou obrigatório; (c) a efetiva abolição do trabalho infantil; e (d) a eliminação da discriminação em matéria de emprego e ocupação. ${ }^{40}$

Os princípios mencionados acima surgem como a base do que virá a ser reconhecido pela OIT como trabalho decente. ${ }^{41}$

Em 1999 surge, então, o conceito do trabalho decente formulado pela OIT, que funciona como a síntese dos objetivos da Organização, a qual possui como missão a promoção do trabalho produtivo e de quali-

37 KANT, Immanuel. Fundamentação da metafísica dos costumes. Lisboa: Edições 70, 2007. p. 69-77.

38 SARLET, Ingo Wolfgang. Dignidade da pessoa bumana e direitos fundamentais na Constituição Federal de 1988. 9. ed. Porto Alegre: Livraria do Advogado, 2012. p. 73.

39 MIRAGLIA, Lívia Mendes Moreira. Trabalho escravo contemporâneo: conceituação à luz do princípio da dignidade da pessoa humana. São Paulo: LTR, 2011. p. 88.

40 ORGANIZAÇÃO INTERNACIONAL DO TRABALHO. Declaração da OIT sobre os princípios e direitos fundamentais no trabalho e seu segmento. Disponível em:<http://www.oit.org.br/sites/default/files/topic/international_labour_standards/pub/declaracao_ oit_293.pdf>. Acesso em: 01 maio 2018.

41 ORGANIZAÇÃO INTERNACIONAL DO TRABALHO. Trabalho decente no Brasil. Disponível em: < http://www.ilo.org/ brasilia/temas/trabalho-decente/lang--pt/index.htm>. Acesso em: 01 mai. 2018. 
dade, em condições de liberdade, equidade, segurança e dignidade humanas, considerado como condição fundamental para a superação da pobreza, a redução das desigualdades sociais, a garantia da governabilidade democrática e o desenvolvimento sustentável. ${ }^{42}$

Portanto, para a OIT, o trabalho decente "é um trabalho produtivo e adequadamente remunerado, exercido em condições de liberdade, equidade e segurança, e que garanta uma vida digna a todas as pessoas que vivem do trabalho e a suas famílias", ou seja, "permite satisfazer às necessidades pessoais e familiares de alimentação, educação, moradia, saúde e segurança". Pode ser entendido também como "emprego de qualidade, seguro e saudável, que respeite os direitos fundamentais do trabalho, garanta proteção social quando não pode ser exercido [...] e assegure uma renda para a aposentadoria". A OIT destaca que o trabalho decente está relacionado à dignidade humana. ${ }^{43}$

Sendo assim, o que se verifica é que o trabalho decente "é aquele em que são respeitados os direitos mínimos do trabalhador, necessários à preservação de sua dignidade"44, vislumbrando desenvolvimento equitativo e integrador, o progresso social e a redução da pobreza. Insta frisar que, para Wandelli, o trabalho decente "representa um padrão mínimo de proteção e não um conceito ótimo ou ideal de trabalho". ${ }^{45}$

Com isso, o acesso ao direito fundamental ao trabalho só pode ser tido concretizado, nos casos em que há a observância às condições mínimas de dignidade do trabalhador, ou seja, na promoção do trabalho decente. Face do discorrido, pode-se asseverar que o trabalho decente é a antítese do trabalho escravo contemporâneo, tema que será abordado a seguir.

\subsection{Trabalho escravo contemporâneo}

O termo "escravidão" é tradicionalmente compreendido como submissão de um indivíduo a outro. O primeiro tratado internacional proibindo a escravidão, firmado pela Liga das Nações Unidas, de 1926, define a escravidão como "o estado e a condição de um indivíduo sobre o qual se exercem, total ou parcialmente, alguns ou todos os atributos do direito de propriedade". ${ }^{46}$

No entanto, o referido conceito sofreu alterações passando a ter mais abrangência, cujas violações aos direitos humanos são expressamente combatidas pelo direito internacional, para o qual não há exceções, como assevera Piovesan:

A proibição do trabalho escravo é absoluta no Direito Internacional dos Direitos Humanos, não contemplando qualquer exceção. Vale dizer, em nenhum caso poderão invocar-se circunstâncias excepcionais, como ameaça ou estado de guerra, instabilidade política interna ou qualquer outra emergência pública, como justificativa par ao tratamento escravo. Tal proibição integra o jus cogens, que é o direito cogente e inderrogável no âmbito internacional. Tal como o direito de não ser submetido à tortura, o direito a não ser submetido à escravidão é um direito absoluto, insuscetível de qualquer relativização ou flexibilização, a não permitir qualquer juízo de ponderação. ${ }^{47}$

42 ORGANIZAÇÃO INTERNACIONAL DO TRABALHO. A OIT no Brasil: trabalho decente para uma vida digna. Disponív-

el em: <http://www.justica.sp.gov.br/StaticFiles/SJDC/ArquivosComuns/ProgramasProjetos/NETP/Relat $\%$ C3\%B3rio. $\% 20$ OIT $\% 20$ no $\% 20$ Brasil.pdf $>$. Acesso em: 01 maio 2018.

43 COMISSÃO ECONÔMICA PARA A AMÉRICA LATINA E O CARIBE; PROGRAMA DAS NAÇÕES UNIDAS PARA O DESENVOLVIMENTO; ORGANIZAÇÃO INTERNACIONAL DO TRABALHO. Emprego, desenvolvimento bumano e trabalho decente: a experiência brasileira recente. Brasília: CEPAL/PNUD/OIT, 2008. p. 12.

44 BRITO FILHO, José Claudio Monteiro de. Trabalho escravo: caracterização jurídica. São Paulo: LTr, 2014. p. 31.

45 WANDELLI, Leonardo Vieira. O direito bumano e fundamental ao trabalho: fundamentação e exigibilidade. São Paulo: LTR, 2012. p. 235.

46 ORGANIZAÇÃO DAS NAÇÕES UNIDAS. Convenção sobre a escravatura assinada em Genebra, em 25 de setembro 1926, e emendada pelo protocolo aberto à assinatura ou à aceitação na sede da Organização das Noções Unidas, Nova York, em 7 de dezembro de 1953. Disponível em:<http://pfdc.pgr.mpf.mp.br/atuacao-e-conteudos-de-apoio/legislacao/trabalho-escravo/convencao_escravatura_genebra_1926.pdf $>$. Acesso em: 01 maio 2018.

47 PIOVESAN, Flávia. Trabalho escravo e degradante como forma de violação dos direitos humanos. In: VELLOSO, Gabriel; FAVA, Marcos Neves. Trabalho escravo contemporâneo: o desafio de superar a negação. São Paulo: LTr, 2006. p. 161-162. 
Ainda no âmbito internacional, a Declaração Universal dos Direitos Humanos, em seu art. $4^{\circ}$, prescreve que "ninguém será mantido em escravatura ou em servidão; a escravatura e o trato dos escravos, sob todas as formas, são proibidos". ${ }^{48}$

A partir do Pacto de São José da Costa Rica, de 1969, estabeleceram-se orientações a serem implementadas pelos Estados signatários no combate à degradação humana, mediante a proibição da escravidão e da servidão:

1.Ninguém pode ser submetido a escravidão ou a servidão, e tanto estas como o tráfico de escravos e o tráfico de mulheres são proibidos em todas as suas formas.

2.Ninguém deve ser constrangido a executar trabalho forçado ou obrigatório. Nos países em que se prescreve, para certos delitos, pena privativa da liberdade acompanhada de trabalhos forçados, esta disposição não pode ser interpretada no sentido de que proíbe o cumprimento da dita pena, imposta por juiz ou tribunal competente. $O$ trabalho forçado não deve afetar a dignidade nem a capacidade física e intelectual do recluso.

3.Não constituem trabalhos forçados ou obrigatórios para os efeitos deste artigo:

a.Os trabalhos ou serviços normalmente exigidos de pessoa reclusa em cumprimento de sentença ou resolução formal expedida pela autoridade judiciária competente. Tais trabalhos ou serviços devem ser executados sob a vigilância e controle das autoridades públicas, e os indivíduos que os executarem não devem ser postos à disposição de particulares, companhias ou pessoas jurídicas de caráter privado;

b.O serviço militar e, nos países onde se admite a isenção por motivos de consciência, o serviço nacional que a lei estabelecer em lugar daquele;

c.O serviço imposto em casos de perigo ou calamidade que ameace a existência ou o bem-estar da comunidade; e

d.O trabalho ou serviço que faça parte das obrigações cívicas normais. ${ }^{49}$

Além disso, o Brasil se comprometeu internacionalmente com as metas do milênio ao ratificar a Declaração do Milênio ${ }^{50}$ aprovada por meio da Resolução n ${ }^{\circ}$. A/55/L.2 da Assembleia Geral das Nações Unidas, que tem, dentre as metas, alcançar o emprego pleno e produtivo e o trabalho decente para todos.

Em âmbito nacional, o Código Penal brasileiro traz, em seu artigo 149, os modos de execução do crime de submeter alguém a trabalho em condições análogas à de escravo. Estes podem ser: típicos (trabalho forçado; jornada exaustiva; trabalho em condições degradantes; trabalho com restrição de locomoção, em razão de dívida contraída) ou por equiparação (retenção no local de trabalho quer por cerceamento do uso de qualquer meio de transporte, pela manutenção de vigilância ostensiva ou pela retenção de documentos e/ ou objetos de uso pessoal do trabalhador). ${ }^{51}$ Portanto, o ilícito do referido dispositivo legal apresenta sete modos de execução, dos quais quatro são típicos e três por equiparação.

Outro detalhe que merece destaque é o de que, em todas as formas de execução do crime, faz-se necessário que exista uma relação de trabalho, marcada por uma sujeição entre o trabalhador e o tomador de serviços, que não se confunde com a subordinação presente nas relações de emprego. Isto porque a sujeição, versada neste artigo, terá a capacidade de anular a vontade do trabalhador por parte do empregador, comprometendo, às vezes, a integridade física e psíquica daquele. ${ }^{52}$

48 ORGANIZAÇÃO DAS NAÇÕES UNIDAS. Declaração universal dos direitos humanos.Disponívelem:<http://www.onu.org.br/ img/2014/09/DUDH.pdf>. Acesso em: 01 maio 2018.

49 BRASIL. Decreto $n^{\circ}$. 678, de 6 de novembro de 1992. Disponívelem:<http://www.planalto.gov.br/ccivil_03/Decreto/D0678. $\mathrm{htm}>$. Acesso em: 8 maio 2018.

50 PROGRAMA DAS NAÇÕES UNIDAS PARA O DESENVOLVIMENTO. Declaração do Milénio. Disponível em: < http:// www.br.undp.org/content/brazil/pt/home/>. Acesso em: 26 jun. 2018.

51 BRITO FILHO, José Claudio Monteiro de. Trabalbo escravo: caracterização jurídica. São Paulo: LTr, 2014. p. 67.

52 BRITO FILHO, José Claudio Monteiro de. Trabalho decente: análise jurídica da exploração do trabalho: trabalho escravo e outras formas de trabalho indigno. 3. ed. São Paulo: LTR, 2013. p. 73-74. 
A imprescindibilidade da investigação em voga se faz visível quando da leitura da pesquisa da Organização Internacional do Trabalho (OIT) e da fundação Walk Free, em parceria com a Organização Internacional para Migração (OIM), a qual apontou que, em 2016, 25 milhões de pessoas foram submetidas a trabalho forçado. ${ }^{53}$ No que concerne ao Brasil, segundo dados do governo brasileiro, no ano de 2015, foram resgatados mais de mil trabalhadores em condições análogas à de escravo. ${ }^{54}$

Por isso, com base no exposto e nos dados supra aludidos, pode-se afirmar que é inegável que toda a prática que culmine no trabalho escravo contemporâneo representa uma afronta a dignidade humana, aos direitos mínimos para a promoção desta, e, portanto, ao trabalho decente, requerendo, assim, a intervenção estatal com mecanismos preventivos, que desestimulem tal prática, uma vez que as vítimas em potencial, geralmente, se encontram em situação de vulnerabilidade social.

\section{Aplicação de nUdges no combate ao trabalhado em Condição anÁlogo à de escravo}

Considerando-se todo o transcurso teórico construído até o momento,na presente pesquisa, pretende-se analisar como e em que medida a Lei n 14.946/2013 (lei Bezerra) e a "lista suja" podem ser identificadas como autênticos nudges no combate ao trabalho escravo contemporâneo.

\subsection{Análise da eficácia da lista suja como desestimulo à utilização do trabalho escravo contemporâneo}

Conforme versado anteriormente, as políticas públicas, na forma de nudges, possuem várias formas de atuação. Dentre as políticas públicas implementadas no Brasil com o escopo de combater a escravidão contemporânea, ganha destaque, em âmbito nacional, um cadastro também denominado de lista suja do trabalho escravo, em que constam os nomes das empresas que utilizam do trabalho em condição análoga à de escravo. ${ }^{55}$

A lista suja foi prevista no Plano Nacional para a Erradicação do Trabalho Escravo, elaborado pela Comissão Nacional para a Erradicação do Trabalho Escravo (Conatrae), e instituído com a Portaria no 540 , de 15 de outubro de 2004.

A publicidade da lista em voga decorre da observância do direito fundamental de acesso à informação (inciso XXXIII do art. $5^{\circ}$, no inciso II do $\int 3^{\circ}$ do art. 37 e no $₫ 2^{\circ}$ do art. 216 da Constituição Federal). Com isso, a política pública (ora tratada ou em testilha), qual seja, a publicidade de lista com o nome das empresas que tenham feito uso de trabalho escravo contemporâneo, tem por escopo impedir que estas recebam financiamentos públicos, e, ainda, pode ser concebida como um desestimulador de tal prática, haja vista que reflete na credibilidade da empresa.

Pelo versado, é possível asseverar que tal cadastro constitui uma política pública que se utiliza de uma das formas de nudge, qual seja, a de informar as pessoas (físicas e/ou jurídicas) sobre a natureza e consequências do passado do empregador, de modo a possibilitar que aquelas façam escolhas racionais, conscientes. Trata-se de medida considerada positiva por especialistas no combate ao trabalho escravo e que encontra respaldo em diversos dispositivos do ordenamento jurídico brasileiro.

53 ORGANIZAÇÃO INTERNACIONAL DO TRABALHO. Mundo tem 40 milhões de pessoas na escravidão moderna e 152 milhões de crianças no trabalho infantil. Disponível em: <http://www.ilo.org/brasilia/noticias/WCMS_575482/lang--pt/index.htm>. Acesso em: 20 maio 2018.

54 BRASIL. Governo Federal. Brasil resgatou mais de mil trabalhadores do trabalho escravo em 2015. 2016. Disponível em: <http:/ / www.brasil. gov.br/cidadania-e-justica/2016/01/brasil-resgatou-mais-de-mil-trabalhadores-do-trabalho-escravo-em-2015.> . Acesso em: 20 maio 2018. 55 A referida política pública foi criada pela Portaria MTE $n^{\circ} 1.234 / 2003$, a qual foi substituída pela Portaria $n^{\circ} 540$, de 15 de outubro de 2004, que, posteriormente, foi revogada pela Portaria Interministerial n ${ }^{\circ}$, de 12 de maio de 2011. Atualmente, a lista suja observa as regras previstas na Portaria Interministerial no 4, de 13 de maio de 2016, que revogou a anterior. 
Entretanto, mesmo diante da importância versada anteriormente, é possível afirmar que a eficácia relativa da lista suja decorre, em parte, do alcance de tal publicidade e seus efeitos, uma vez que a eficácia desta está condicionada a uma escolha voltada para o reconhecimento pelo consumidor e contratante (ou celebrante de acordos congêneres) da dignidade daquele que, por meio de seu trabalho, produz o produto a ser adquirido. Ou seja, exigiria uma pesquisa, bem como que o consumidor ignorasse os valores dispendidos para a compra de determinado bem, uma vez que levaria em consideração, no processo de ponderação, as condições a que a pessoa humana foi submetida para a produção da mercadoria, e não apenas a comparação de valores, pois, na maioria das vezes, produtos produzidos com a mão de obra em condição análoga à de escravo são inferiores aos de empresas que promovem o trabalho decente.

Nessa esteira, se faz possível defender que políticas governamentais pautadas no que se denomina de análise econômico comportamental do direito possuem maior aplicabilidade, uma vez que, quando direcionada aos empresários, surtem mais efeitos. Isso pois aquele que detém os meios de produção poderia ser induzido à promoção e proteção do trabalho decente pela benesse de receber as mais diversas formas de incentivos fiscais.

No cenário nacional, não se denotam muitas políticas governamentais pautadas no incentivo versado, mas sim em medidas sancionatórias. O discorrido propicia que, financeiramente, seja embora arriscado, mais vantajoso descumprir gravemente as normas que versam sobre proteção e promoção do trabalho digno, tendo em vista que o empregador atuará na margem de riscos, calculando os ganhos e perdas. Essa última é uma probabilidade que pode nunca ocorrer, principalmente em razão da falta de estrutura para a realização de fiscalização pelo órgão público competente para tanto.

\section{2. $O$ impacto da Lei $n^{\circ}$ 14.946/2013 (Lei Bezerra) para a proteção do trabalhador}

O item anterior abordou uma dentre as inúmeras normas aplicáveis ao combate do trabalho em condições análogas à de escravo no Brasil, nesse momento, nos deteremos à análise de uma medida regional. Para tal intento, optamos por colocar em debate a Lei Estadual nº 14. 946 de 28 de janeiro de 2013, regulamentada pelo Estado de São Paulo, por meio do Decreto Estadual no. 59.171, de 13 de maio de 2013. A lei supracitada dispõe acerca da cassação da inscrição no cadastro de contribuintes do Imposto sobre Operações Relativas à Circulação de Mercadorias e sobre Prestações de Serviços de Transporte Interestadual e Intermunicipal e de Comunicação - ICMS, "de qualquer empresa que faça uso direto ou indireto de trabalho escravo ou em condições análogas". ${ }^{56}$

O Estado de São Paulo, talvez, em razão de concentrar elevado número de empresas que utilizam de mão de obra em condições de escravidão contemporânea, tem se mostrado pioneiro no que tange a ações (relacionadas às regulamentações) de prevenção e repressão do trabalho em condição análoga à de escravo, pois, além da lei versada anteriormente, promulgou, também, a Lei Municipal nº 16.606, de 29 de dezembro de 2016. Por meio da mencionada lei, foram acrescidos os " $\iint 5^{\circ}, 6^{\circ}, 7^{\circ}, 8^{\circ}$ e $9^{\circ}$ ao art. $6^{\circ}$ da Lei $n^{\circ} 10.205$, de 4 de dezembro de 1986, que disciplina a expedição de licença de funcionamento", de modo a prever a possibilidade de que os estabelecimentos que forem responsabilizados pela utilização do trabalho escravo contemporâneo poderão “sofrer" multa de R \$100.000,00 (cem mil reais) a R \$ 100.000.000,00 (cem milhões de reais) e ter cassada a licença de funcionamento- Nesse último caso, devem estar presentes os requisitos de reincidência, "ou da comprovação da extrema gravidade da conduta, na forma de regulamento, respeitado o procedimento previsto no $₫ 7^{\circ}$ ". ${ }^{57}$

A Lei Bezerra prevê que as empresas condenadas por trabalho escravo, em segunda instância, nas esferas

56 SÃO PAULO (Estado). Lei no. 14.946, de 28 de janeiro de 2013. Disponível em: <https://www.al.sp.gov.br/repositorio/legislacao/lei/2013/lei-14946-28.01.2013.html>. Acesso em: 1 maio 2018.

57 SÃO PAULO. Câmara Municipal. Lei no . 16.606, de 29 de dezembro de 2016. Disponívelem:<http:/ /documentacao.camara.sp.gov. br/iah/fulltext/leis/L16606.pdf>. Acesso em: 1 maio 2018. p. 1. 
trabalhista ou criminal, tenham o registro do ICMS (Imposto sobre Circulação de Mercadorias e Serviços) suspenso por dez anos. Sem o qual não é possível comercializar no Estado. Além disso, seus proprietários ficam impedidos, por igual período, de exercer o mesmo ramo de atividade econômica ou entrarem com pedido de inscrição de nova empresa, no mesmo ramo de atividade.

Por essas razões, pode-se identificar a Lei nº 14. 946/2013 como um nudge, empurrão ou estímulo de comportamento a qualquer empresa do Estado de São Paulo que faça uso direto ou indireto de trabalho escravo ou em condições análogas. Essa forma de nudge se enquadraria no que Sunsteins ${ }^{58}$ denominou de uso de normas sociais e isso pode ser compreendido, principalmente, em razão do caráter punitivo e do medo da perda ${ }^{59}$ que a referida lei, se aplicada, pode ocasionar.

Significa dizer que, se os empresários paulistas não quiserem perder suas inscrições no cadastro dos contribuintes, bem como outras formas de punição, devem promover o trabalho decente, zelar pela qualidade do ambiente de trabalho, respeitar e garantir a dignidade da pessoa humana do trabalhador, zelar pelo cumprimento das normas trabalhistas e constitucionais.

Mister se faz mencionar, em razão da aplicabilidade do nudge ora tratado, a decisão proferida pela $54^{a}$ Vara do Trabalho de São Paulo que condenou a M5 Indústria e Comércio, dona da marca M.Officer, em ação civil pública proposta em 2014 pelo Ministério Público do Trabalho de São Paulo (MPT-SP), ao pagamento de $\mathrm{R} \$ 4$ milhões pelos danos morais coletivos e $\mathrm{R} \$ 2$ milhões pela prática de dumping social e a possível cassação da inscrição no cadastro de contribuintes de ICMS, depois da decisão de segunda instância — já que, a partir disso, a Secretaria de Fazenda do Estado de São Paulo será oficiada para dar início ao procedimento administrativo de cassação com base na lei bezerra — por submeter trabalhadores a condições análogas à escravidão $^{60}$.

$\mathrm{Na}$ decisão de $2^{\circ}$ grau, o TRT da $2^{a}$ Região manteve por unanimidade a decisão de $1^{\circ}$ grau, condenando a empresa M5 Indústria e Comércio. Nesse ínterim tudo indica que em breve a Secretaria de Fazenda do Estado de São Paulo será oficiada para dar início ao procedimento administrativo de cassação da inscrição no cadastro de contribuintes de ICMS com base na lei bezerra.

Isso denota, indubitavelmente, um avanço significativo no combate ao trabalho escravo contemporâneo. Além das condenações monetárias e de obrigações de fazer da empresa (que incluem cumprimento das leis trabalhistas), esta por meio de um nudge do Estado de São Paulo terá suas atividades suspensas por um considerado lapso temporal. E com isso um estímulo a um comportamento que promova o trabalho decente, reconheça a dignidade do trabalhador e o valor social do trabalho foi promovido e certamente isso refletirá nas próximas ações da empresa no que concerne ao cumprimento e respeito das leis do trabalho.

O nudge em comento é uma forma de se incentivar o cumprimento da legislação e zelar pela vida digna dos trabalhadores, pois, dessa forma, os outros empresários também poderão avaliar, com a arquitetura do futuro, se pretendem correr o risco de serem penalizados ${ }^{61}$.

Por derradeiro podemos verificar a eficácia da aplicação da análise econômica comportamental do direito, mormente dos nudges, em vários contextos e com diferentes finalidades. O presente trabalho permitiu corroborar a premissa de que se os nudges formulados através de políticas públicas forem formulados, a par-

58 SUNSTEIN, Cass R. Nudging: a very short guide. p. 3-6. Disponível em: < https://papers.ssrn.com/sol3/papers.cfm?abstract_ id $=2499658>$. Acesso em: 29 abr. 2018.

59 As pessoas possuem maior aversão ao risco de perder do que afeição por ganhar. Isso porque o ser humano costuma dar maior peso à derrota do que para a vitória.

60 SÃO PAULO. Tribunal Regional do Trabalho da $2^{\circ}$ região. Recurso Ordinário. RO $n^{\circ}$. 0001779550145020054. Relator: Ricardo Artur Costa e Trigueiros. Disponível em: < https://trt-2.jusbrasil.com.br/jurisprudencia/520126000/17795520145020054sao-paulo-sp/inteiro-teor-520126003>. Acesso em: 02 maio 2018.

61 FRANCO, Claudia Regina Lovato; TABAK, Benjamim Miranda; BIJOS, Leila. A lei no 14.946/2013 (lei bezerra): um nudge para incentivar empresários do setor de confecção da indústria paulista a cumprirem as leis trabalhistas. Revista de Direito Brasileira, São Paulo, v. 16, n. 7, p. 346-362, jan./abr. 2017. 
tir de uma perspectiva transdisciplinar, sistêmica e preservando-se a liberdade de escolha, podem conduzir a comportamentos considerados melhores ou mais adequados, e também possibilitou concluir que essa forma de empurrão comportamental, mormente em forma de incentivo e não apenas de sanção, pode ser uma forma mais eficaz de prevenção e combate ao trabalho análogo ao escravo no Brasil.

\section{Considerações finais}

O presente estudo possibilitou comprovar a necessidade da transversalidade como forma de se entender o problema a partir da sua complexidade, além disso, permitiu verificar que a Análise Econômica do Direito e a Análise Econômica do Direito Comportamental possibilitaram um novo olhar da Teoria Econômica Tradicional e uma nova percepção sobre o processo de escolhas do ser humano.

Ante pese contradições na forma com que cada teoria enxerga o processo de tomada de decisão, uma focada na racionalidade exacerbada e na literalidade da análise custo-benefício, outra em vieses e influencias endógenas e exógenas ao indivíduo, que pressupõe que na verdade nunca estamos totalmente livres quando realizamos escolhas, uma vez que, de alguma forma, somos influenciados por algo ou alguém, ambas proporcionaram uma nova ótica: a arquitetura das escolhas — e como uma estruturação adequada dessa podem conduzir a comportamentos mais desejáveis.

Quando verificamos essa nova ótica ser materializada por meio da elaboração e implementação de políticas públicas que atuam como nudges, podemos ter a confirmação da imprescindibilidade de estudos transdiciplinares abordando economia, direito e psicologia comportamental.

Outrossim, quando, por meio dos estudos supra aludidos, aferimos a possibilidade de utilizar da análise comportamental para anteceder comportamentos a fim de se garantir a promoção do trabalho decente, a valorização da dignidade humana do trabalhador e do valor social do trabalho, caminhamos mais comprometidos com a salvaguarda e o cumprimento desses direitos e, dessa forma, também com o combate ao trabalho escravo contemporâneo.

Por essas razões, as elaborações de medidas governamentais, inclusive leis, que tenham finalidade de nudge, por meio de uma abordagem de estímulo e não apenas sancionatória, voltadas ao cumprimento das normas trabalhistas, nos colocará, cada dia, mais próximos da erradicação do trabalho que mais explora a vulnerabilidade humana.

O trabalho escravo contemporâneo é ainda significativamente incidente no Brasil. É um trabalho que viola muito mais do que os direitos trabalhistas, fere brutalmente os direitos humanos no aspecto individual e coletivo, por isso, deve ser causa comum à sociedade a compreensão de sua configuração e o engajamento no combate as práticas que o configuram, seja na forma de execução típica ou por equiparação.

Por fim, cumpre registrar que se denota, no âmbito brasileiro, a adoção majoritária por parte dos poderes públicos, de políticas públicas pautadas em medidas sancionatórias, o que, frisa-se, não retira os seus méritos. No entanto, se faz imperioso mencionar que a implementação de políticas baseadas no nudge como um incentivo, por meio de benefícios advindos da observância das normas trabalhistas e, portanto, da promoção do trabalho decente, propiciaria, talvez, mais eficácia do que, apenas, a prática condenatória.

\section{REFERÊNCIAS}

ALVAREZ, Alejandro Buagllo. Análise econômica do direito: contribuições e desmistificações. Revista Direito, Estado e Sociedade, v.9, n.29, p. 49-68, jul./dez. 2006. 
AMBROSINO, A. Faralla V.; NOVARESE, M. Nudge: a critical perspective. In: MARCIANO, A.; RAMELLO, G. (Eds.). Enciclopédia de Direito e Economia. New York: Springer, 2018. Disponível em: < https://doi. org/10.1007/978-1-4614-7883-6_631-1>. Acesso em: 30 abr. 2018.

ANDAKU, Juliana Almenara. O direito na teoria de Niklas Lubmann. Disponível em: <www.agu.gov.br/page/ download/index/id/692917>. Acesso em: 21 maio 2018.

ANDRADE, Mariana Dionísio de; REMÍGIO, Rodrigo Ferraz de Castro. Políticas Públicas e escolha racional: o caso do Centro Urbano de Cultura, Arte, Ciência e Esporte de Fortaleza, estado do Ceará. Rev. Bras. de Políticas Públicas, Brasília, v. 7, n. 2, p. 259-265, ago. 2017.

ÁVILA, Flávia; BIANCHI, Ana Maria. Guia de economia comportamental e experimental. São Paulo: economia comportamental.org., 2015.

BARONE, Fernando. Sociedade e escola: Niklas Luhmann e a abordagem sistêmica. Ponto e vírgula - Revista das Ciências Sociais, São Paulo, n. 12, p. 5-32, 2013. Disponível em: < https://revistas.pucsp.br/index.php/ pontoevirgula/article/viewFile/12678/12310>. Acesso em: 20 maio 2018.

BOBBIO, Norberto. Teoria da norma jurídica. 2. ed. São Paulo: Edipro, 2008.

BRANCALEON, Brigida Batista et. al. Políticas públicas: conceitos básicos. São Paulo: Universidade de São Paulo, 2015.

BRASIL. Constituição (1988). Constituição da República Federativa do Brasil. Disponívelem:<http://www.planalto.gov.br/ccivil_03/constituicao/constituicao.htm>. Acesso em: 8 maio 2018.

BRASIL. Decreto $n^{\circ}$ 58.563, de $1^{\circ}$ de junho de 1966. Disponívelem:<http://www2.camara.leg.br/legin/fed/ decret/1960-1969/decreto-58563-1-junho-1966-399220-publicacaooriginal-1-pe.html>. Acesso em: 8 maio 2018.

BRASIL. Decreto n. 678, de 6 de novembro de 1992. Disponívelem:<http://www.planalto.gov.br/ccivil_03/ Decreto/D0678.htm>. Acesso em: 8 maio 2018.

BRASIL. Governo Federal. Brasil resgatou mais de mil trabalhadores do trabalho escravo em 2015. 2016. Disponível em: <http://www.brasil.gov.br/cidadania-e-justica/2016/01/brasil-resgatou-mais-de-mil-trabalhadoresdo-trabalho-escravo-em-2015.>. Acesso em: 20 maio 2018.

BRITO FILHO, José Claudio Monteiro de. Trabalho decente: análise jurídica da exploração do trabalho: trabalho escravo e outras formas de trabalho indigno. 3. ed. São Paulo: LTR, 2013.

BRITO FILHO, José Claudio Monteiro de. Trabalho escravo: caracterização jurídica. São Paulo: LTr, 2014.

CAMBRIDGE INTERNATIONAL. Dictionary of English. New York: CUP, 2000.

COMISSÃO ECONÔMICA PARA A AMÉRICA LATINA E O CARIBE; PROGRAMA DAS NAÇÕES UNIDAS PARA O DESENVOLVIMENTO; ORGANIZAÇÃO INTERNACIONAL DO TRABALHO.

Emprego, desenvolvimento bumano e trabalho decente: a experiência brasileira recente. Brasília: CEPAL/PNUD/ OIT, 2008.

CUNHA, Bruno Santos. Direitos fundamentais: da constituição às políticas públicas. Rev. Bras. Políticas Públicas, Brasília, v. 1, n. 1, p. 65-82, jan./jun. 2011.

FERREIRA, Felipe Furtado; POTTUMATI, Eduardo Carlos. A licitação pública como instrumento de desenvolvimento na perspectiva do paternalismo libertário. Rev. Bras. Políticas Públicas, Brasília, v. 4, n. 1, p. 201-215, jan./jun. 2014.

FRANCO, Claudia Regina Lovato; TABAK, Benjamim Miranda; BIJOS, Leila. A lei no 14.946/2013 (lei bezerra): um nudge para incentivar empresários do setor de confecção da indústria paulista a cumprirem as leis trabalhistas. Revista de Direito Brasileira, São Paulo, v. 16, n. 7, p. 346-362, jan./abr. 2017. 
KANT, Immanuel. Fundamentação da metafísica dos costumes. Lisboa: Edições 70, 2007.

KRUGMAN, Paul R. Introdução à economia. Rio de Janeiro: Elsevier, 2007.

KUNZLER, Caroline de Morais. A teoria dos sistemas de Nicklan Luhmann. Estudos de Sociologia, Araraquara, v. 16, p. 123-136, 2004. Disponível em: <https://periodicos.fclar.unesp.br/estudos/article/viewFile/146/144>. Acesso em: 20 maio 2018.

LUHMANN, Niklas. Introdução à teoria dos sistemas. 3. ed. Petrópolis: Vozes, 2011.

MELLO, Vera Rita de. Psicologia econômica: estudo do comportamento econômico e da tomada de decisão. Rio de Janeiro: Campus-Elsevier, 2008.

MENEGAZZI, Piero Rosa. A efetivação do direito à informação no meio ambiente de trabalho: contribuições do pensamento sistêmico, da teoria da complexidade e do estudo dos riscos. São Paulo: LTr, 2011.

MIRAGLIA, Lívia Mendes Moreira. Trabalho escravo contemporâneo: conceituação à luz do princípio da dignidade da pessoa humana. São Paulo: LTR, 2011.

ORGANIZAÇÃO DAS NAÇÕES UNIDAS. Declaração universal dos direitos humanos.Disponívelem:<http:// www.onu.org.br/img/2014/09/DUDH.pdf>. Acesso em: 01 maio 2018.

ORGANIZAÇÃO INTERNACIONAL DO TRABALHO. A OIT no Brasil: trabalho decente para uma vida digna. Disponível em: <http://www.justica.sp.gov.br/StaticFiles/SJDC/ArquivosComuns/ProgramasProjetos/NETP/Relat\%C3\%B3rio.\%20OIT\%20no\%20Brasil.pdf>. Acesso em: 01 maio 2018.

ORGANIZAÇÃO INTERNACIONAL DO TRABALHO. Declaração da OIT sobre os princípios e direitos fundamentais no trabalbo e seu segmento. Disponível em: <http://www.oit.org.br/sites/default/files/topic/international_labour_standards/pub/declaracao_oit_293.pdf>. Acesso em: 01 maio 2018.

ORGANIZAÇÃO INTERNACIONAL DO TRABALHO. Mundo tem 40 milhões de pessoas na escravidão moderna e 152 milhöes de crianças no trabalho infantil. Disponível em: < http://www.ilo.org/brasilia/noticias/ WCMS_575482/lang--pt/index.htm>. Acesso em: 20 maio 2018.

ORGANIZAÇÃO INTERNACIONAL DO TRABALHO. Trabalho decente no Brasil. Disponível em: <http://www.ilo.org/brasilia/temas/trabalho-decente/lang--pt/index.htm>. Acesso em: 01 mai. 2018.

PAPP, Leonardo. Análise econômica do direito e a (re) inserção da eficácia na teoria do direito. Revista da Associação Mineira de Direito e Economia, Belo Horizonte, v. 9, p. 60-87, jul. 2012. Disponível em: <www.revista. amde.org.br/index.php/ramde/article/download/89/pdf>. Acesso em: 25 abr. 2018.

PIOVESAN, Flávia. Trabalho escravo e degradante como forma de violação dos direitos humanos. In: VELLOSO, Gabriel; FAVA, Marcos Neves. Trabalho escravo contemporâneo: o desafio de superar a negação. São Paulo: LTr, 2006.

PORTO, Antônio José Maristrello. Análise econômica do direito. 2013. Disponívelem: $<$ http://direitorio.fgv. br/sites/direitorio.fgv.br/files/u100/analise_economica_do_direito_20132.pdf>. Acesso em: 15 abr. 2018.

PROGRAMA DAS NAÇÕES UNIDAS PARA O DESENVOLVIMENTO. Declaração do Milênio. Disponível em: <http://www.br.undp.org/content/brazil/pt/home/>. Acesso em: 26 jun. 2018.

RODRIGUES, Vasco. Análise econômica do direito: uma introdução. Coimbra: Gráfica Coimbra, 2007.

SÃO PAULO (Estado). Lei no. 14.946, de 28 de janeiro de 2013. Disponível em: < https://www.al.sp.gov.br/ repositorio/legislacao/lei/2013/lei-14946-28.01.2013.html>. Acesso em: 1 maio 2018.

SÃO PAULO. Câmara Municipal. Lei ñ. 16.606, de 29 de dezembro de 2016. Disponívelem: $<$ http://documentacao.camara.sp.gov.br/iah/fulltext/leis/L16606.pdf>. Acesso em: 1 maio 2018.

SARLET, Ingo Wolfgang. Dignidade da pessoa bumana e direitos fundamentais na Constituição Federal de 1988. 9. ed. 
Porto Alegre: Livraria do Advogado, 2012.

SCALEA, José Augusto; TABAK, Benjamin Miranda. Direito de propriedade intelectual: formas de proteção, seu impacto no desenvolvimento econômico e propostas para sua melhoria. Revista de Direito Econômico e Socioambiental, Curitiba, v. 7, n. 2, p. 154-174, jul./dez. 2016. Disponível em: < https://periodicos.pucpr.br/ index.php/direitoeconomico/article/view/5837>. Acesso em: 30 abr. 2018.

SEIDL, D.; BECKER, K. H. Organizations as Distinction Generating and Processing Systems: Niklas Luhmann's Contribution to Organization Studies. Organizations. Sage Journal, v. 13, n. 1, p. 9-35, 2006. Disponível em: <http://journals.sagepub.com/doi/pdf/10.1177/1350508406059635>. Acesso em: 9 maio 2018.

SHILLER, R. J. Behavioral Economics and Institutional Innovation. Southern Economic Journal, v. 72, n. 2, 2005. Disponível em: <http://www.econ.yale.edu/ shiller/pubs/p1150.pdf>. Acesso em: 9 maio 2018.

SIMON, Herbert A. A behavioral model of rational choice. The Quarterly Journal of Economics, v.69, n.1, p.99118, fev. 1955. Disponível em: <http://www.math.mcgill.ca/vetta/CS764.dir/bounded.pdf>. Acesso em: 9 maio 2018.

SOUTO MAIOR, Jorge Luiz; MOREIRA, Ranúlio Mendes Moreira; SEVERO, Valdete Souto. Dumping social nas relaçoes de trabalho. São Paulo: LTr, 2012

SOUZA, C. Política Públicas: uma revisão da literatura. Sociologias, Porto Alegre, ano 8, n. 16, p. 20-45, jun./ dez. 2006. Disponível em: <http://www.scielo.br/pdf/soc/n16/a03n16>. Acesso em: 15 abr. 2018.

STIGLER, George. "Law or Economics?”. The Journal of Law and Economics, v. 35, n. 2, p. 455-468, out. 1992. Disponível em: <https://www.jstor.org/stable/725548?seq=1\#page_scan_tab_contents>. Acesso em: 15 abr. 2018.

SUNSTEIN, Cass R. It's for your own good! Disponível em: <http://www.nybooks.com/articles/archives/2013/mar/07/its-your-own-good/?pagination=false>. Acesso em: 20 maio 2018.

SUNSTEIN, Cass R. Nudging: a very short guide. Disponível em: < https://papers.ssrn.com/sol3/papers. cfm?abstract_id=2499658>. Acesso em: 29 abr. 2018.

TABAK, Benjamim Miranda. A análise econômica do direito: proposições legislativas e políticas públicas. Revista de informação legislativa, Brasília, ano 52, n. 205, p. 321-345 jan./mar. 2015.

THALER, Richard H.; SUNSTEIN, Cass R. Nudge: o empurrão para a escolha certa: aprimore suas decisões sobre saúde, riqueza e felicidade. Rio de Janeiro: Elsevier, 2009.

WANDELLI, Leonardo Vieira. O direito bumano e fundamental ao trabalho: fundamentação e exigibilidade. São Paulo: LTR, 2012. 
Para publicar na revista Brasileira de Políticas Públicas, acesse o endereço eletrônico www.rbpp.uniceub.br

Observe as normas de publicação, para facilitar e agilizar o trabalho de edição. 